\title{
Ambiguity and the multinational firm
}

\author{
Kit Pong Wong* \\ School of Economics and Finance, University of Hong Kong, Pokfulam Road, Hong Kong
}

\begin{abstract}
This paper examines the optimal production and hedging decisions of the multinational firm under exchange rate uncertainty when the multinational firm possesses smooth ambiguity preferences. Ambiguity is modeled by a second-order probability distribution that captures the multinational firm's uncertainty about which of the subjective beliefs govern the exchange rate risk. Ambiguity preferences are modeled by the (second-order) expectation of a concave transformation of the (firstorder) expected utility of home currency profit conditional on each plausible subjective distribution of the exchange rate risk. Within this framework, we show that the separation and full-hedging theorems are robust to the incorporation of ambiguity and ambiguity preferences. The presence of the currency hedging opportunity induces the multinational firm to produce more and sell less at home, and export more abroad. When the forward exchange rate is biased, we derive necessary and sufficient conditions under which the multinational firm optimally opts for a forward position that is closer to a full-hedge in response to either the introduction of ambiguity or greater ambiguity aversion.
\end{abstract}

JEL classification: D81; F23; F31

Keywords: Ambiguity; Ambiguity aversion; Currency hedging; Multinational firms

\section{Introduction}

Multinational firms take exchange rate risk management seriously. In an extensive survey of Fortune 500 firms, Jesswein et al. (1995) document the extent of knowledge and use of exchange rate risk management products by these firms. They show that currency forward contracts are the most popular hedging instruments that are adopted by 93.1 percent of respondents of the survey. The next commonly used hedging instruments are foreign currency swaps (52.6 percent) and over-the-counter currency options (48.8 percent). Recent innovative exchange rate risk management products such as compound options (3.8

\footnotetext{
${ }^{*}$ Tel.: +852 2859 1044; fax: +852 25481152 .

E-mail address: kpwong@econ.hku.hk (K.P. Wong).
} 
percent) and look-back options (5.1 percent) are among the least extensively used hedging instruments. The Jesswein et al. (1995) survey suggests that most multinational firms meet their exchange rate risk management needs by relying solely on currency forward contracts that are not supplanted by more complicated innovations. ${ }^{1}$

The study of the multinational firm under exchange rate uncertainty has been the subject of considerable research in decision making under uncertainty (Broll, 1992; Broll and Zilcha, 1992; Choe et al., 2015; Katz and Paroush, 1979; Kawai and Zilcha, 1986; Lien and Wong, 2005; Meng and Wong, 2007; Viaene and Zilcha, 1998; Wong, 2012, 2013). The extant literature assumes that the multinational firm's preferences admit the standard von Neumann-Morgenstern expected utility representation. When the multinational firm has access to a forward market for currency hedging purposes, two celebrated results emanate. First, the separation theorem states that the multinational firm's production and export decisions depend neither on the risk attitude of the multinational firm, nor on the incidence of the exchange rate uncertainty. Second, the full-hedging theorem states that the multinational firm fully hedges against its risk exposure to the exchange rate uncertainty should the forward market be unbiased.

In reality, multinational firms may not be able to unambiguously assign a probability distribution that uniquely describes the exchange rate risk. To this end, we define uncertainty in the sense of Knight (1921) to be made up of two components, risk and ambiguity. ${ }^{2}$ Risk aversion is the aversion to a set of outcomes with a known probability distribution. Ambiguity aversion is the additional aversion to being unsure about the probabilities of outcomes. Dated back to the Ellsberg's (1961) paradox, ambiguity has been alluded to the violation of the independence axiom, which is responsible for the decision criterion being

\footnotetext{
${ }^{1}$ In a survey conducted by the Wharton School of the University of Pennsylvania, 83 percent of large firms hedge against commodity, currency, and interest rate risk, whereas only 45 percent of medium firms and 12 percent of small firms do so. Multinational firms are clearly in the category of large firms. See Bodnar et al. (1998).

${ }^{2}$ Knight (1921) points out that ambiguity is fundamentally different from risk. Specifically, risk relates to objective uncertainty, where outcome probabilities are known or can be estimated with confidence. In contrast, ambiguity relates to subjective uncertainty, where outcome probabilities are unknown, and decision makers are not sure which estimated models are correct.
} 
linear in the outcome probabilities. ${ }^{3}$ The distinction between the known-unknown and the unknown-unknown is relevant since individuals appear to prefer gambles with known rather than unknown probabilities. Indeed, ample experiments (Chow and Sarin, 2001; Einhorn and Hogarth, 1986; Sarin and Weber, 1993) and surveys of business owners and managers (Chesson and Viscusi, 2003; Viscusi and Chesson, 1999) have documented convincing evidence that ambiguity aversion prevails.

Klibanoff et al. (2005) have recently developed a powerful decision criterion known as "smooth ambiguity aversion" that is compatible with ambiguity averse preferences under uncertainty (hereafter referred to as the KMM model). The KMM model features the recursive structure that is far more tractable in comparison to other models of ambiguity such as the pioneering maxmin expected utility (or multiple-prior) model of Gilboa and Schmeidler (1989). ${ }^{4}$ Specifically, the KMM model represents ambiguity by a second-order probability distribution that captures a decision maker's uncertainty about which of the subjective beliefs govern the underlying risk. The KMM model then measures the decision maker's expected utility under ambiguity by taking the (second-order) expectation of a concave transformation of the (first-order) expected utility conditional on each plausible subjective distribution of the underlying risk. This recursive structure creates a crisp separation between ambiguity and ambiguity aversion, i.e., between beliefs and tastes, which allows us to study these two attributes independently. Another nice feature of the KMM model is that we can apply the conventional techniques in the decision making under uncertainty in the context of ambiguity (Alary et al., 2013; Broll and Wong, 2015; Cherbonnier and Gollier,

\footnotetext{
${ }^{3}$ A vivid description of the Ellsberg's (1961) paradox is from Keynes (1921). Consider the following experiment with two urns, $\mathrm{K}$ and U. Urn K contains 50 red balls and 50 blue balls. Urn U contains 100 balls (all balls are either red or blue), but the exact numbers of red and blue balls are not disclosed. Subjects are asked to select from which urn they would like to draw a ball. They are rewarded if the color of their choice is drawn. In this experiment, subjects typically select urn $\mathrm{K}$, revealing aversion to ambiguity. To see this, suppose that subjects believe that the probability of drawing a blue ball from urn $\mathrm{U}$ is $p$. Subjects should prefer to draw a red ball or a blue ball from urn $\mathrm{U}$ than from urn $\mathrm{K}$, depending on whether $p$ is smaller or greater than $1 / 2$, respectively. If $p=1 / 2$, subjects should be indifferent between the two urns. Since subjects choose to draw from urn K, such paradoxical behavior can only be rationalized by allowing multiple priors to be held by subjects on urn U. See also Dillenberger and Segal (2015) and Machina (2014).

${ }^{4}$ Skiadas (2013) shows that smooth ambiguity preferences can be approximated by preferences admitting an expected utility representation in continuous-time or high-frequency models under Brownian or Poisson uncertainty.
} 
2015; Gollier, 2011; Snow, 2010, 2011; Taboga, 2005; Treich, 2010; Wong, 2015a, 2015b).

In this paper, we incorporate the KMM model into the multinational firm under exchange rate uncertainty à la Broll and Zilcha (1992) by assuming that the multinational firm possesses smooth ambiguity preferences. Specifically, the multinational firm produces in the home country and sells its output in both the home and foreign markets. The multinational firm is ambiguous about the distribution of the random spot exchange rate between the home and foreign currencies. To hedge against the exchange rate risk, the multinational firm can trade the foreign currency forward at a predetermined forward exchange rate. We show that the separation and full-hedging theorems are robust to the incorporation of ambiguity and ambiguity preferences. As long as the multinational firm optimally sells the foreign currency forward, we show that the availability of the currency hedging opportunity induces the multinational firm to produce more and sell less at home, and export more abroad. When the predetermined forward exchange rate is biased in that it is different from the objective expected spot exchange rate, we derive necessary and sufficient conditions under which the multinational firm optimally opts for a forward position that is closer to a full-hedge in response to either the introduction of ambiguity or greater ambiguity aversion. These necessary and sufficient conditions hold when the multinational firm's coefficient of relative risk aversion does not exceed unity and its subjective beliefs are ranked in the sense of first-order stochastic dominance. ${ }^{5}$

While most of the results in this paper are consistent with the findings of the extant literature under risk aversion, subtle differences arise when ambiguity and ambiguity aversion prevail. First, risk aversion does not allow for ambiguity so that the multinational firm's reaction to ambiguity cannot be studied. Second, we show that greater ambiguity aversion may induce the multinational firm to opt for a forward position that is further away from a full-hedge when the forward exchange rate is biased, which is in stark contrast to the case of greater risk aversion. These suggest that the distinction between risk aversion and

\footnotetext{
${ }^{5}$ Barham et al. (2014) document that the average coefficient of relative risk aversion is 0.8 in their sample of Midwestern grain farmers in the U.S., which is in line with the magnitudes of relative risk aversion found in many developing countries (Cardenas and Carpenter, 2008).
} 
ambiguity aversion and that between the known-unknown and the unknown-unknown are important considerations to better understand the behavior of the multinational firm.

The rest of this paper is organized as follows. Section 2 delineates the KMM model of the multinational firm under exchange rate uncertainty. Section 3 characterizes the solution to the model. Section 4 examines the effect of currency hedging on the multinational firm's production and export decisions. Section 5 examines how ambiguity and ambiguity aversion affect the multinational firm's optimal forward position. The final section concludes.

\section{The model}

Consider the multinational firm under exchange rate uncertainty $\grave{a}$ la Broll and Zilcha (1992) in the context of the KMM model. There is one period with two dates, 0 and 1. To begin, the multinational firm produces a single commodity in the home country according to a deterministic cost function, $C(Q)$, where $Q \geq 0$ is the output level, and $C(Q)$ is compounded to date 1 with the properties that $C(0)=C^{\prime}(0)=0$, and $C^{\prime}(Q)>0$ and $C^{\prime \prime}(Q)>0$ for all $Q>0 .{ }^{6}$ The multinational firm commits to selling $Q_{1}$ units of its output at home and exporting $Q_{2}$ units to a foreign country, where $Q_{1} \geq 0, Q_{2} \geq 0$, and $Q_{1}+Q_{2}=Q$

The multinational firm's domestic sales generate home currency revenues at date 1 specified by a deterministic revenue function, $R_{1}\left(Q_{1}\right)$. On the other hand, the multinational firm's exports generate foreign currency revenues at date 1 specified by another deterministic revenue function, $R_{2}\left(Q_{2}\right)$. We assume that $R_{i}(0)=0, \lim _{Q_{i} \rightarrow 0} R_{i}^{\prime}\left(Q_{i}\right)=\infty$, and $R_{i}^{\prime}\left(Q_{i}\right)>0$ and $R_{i}^{\prime \prime}\left(Q_{i}\right)<0$ for all $Q_{i} \geq 0$ and $i=1$ and 2 . Due to the segmentation of the home and foreign markets, arbitrage transactions are either impossible or unprofitable, thereby

\footnotetext{
${ }^{6}$ The strict convexity of the cost function reflects the fact that the multinational firm's production technology exhibits decreasing returns to scale. Our qualitative results remain intact if the multinational firm can produce the commodity in both the home and foreign countries according to the respective deterministic cost functions, as in Broll and Zilcha (1992).
} 
invalidating the law of one price. ${ }^{7}$

We model the exchange rate uncertainty in a reduced form by a random variable, $\tilde{S}$, that denotes the unknown spot exchange rate at date $1^{8} \tilde{S}$ is expressed in units of the home currency per unit of the foreign currency, and is distributed according to an objective cumulative distribution function $(\mathrm{CDF}), F^{\circ}(S)$, over support $[\underline{S}, \bar{S}]$, where $0 \leq \underline{S}<\bar{S} \leq \infty$. To hedge against $\tilde{S}$, the multinational firm can sell (purchase if negative) $X$ units of the foreign currency forward at the forward exchange rate, $S^{f}$, predetermined at date 0 , where $\underline{S}<S^{f}<\bar{S}$. The multinational firm's home currency profit at date 1 is, therefore, given $\mathrm{by}^{9}$

$$
\tilde{\Pi}=R_{1}\left(Q_{1}\right)+\tilde{S} R_{2}\left(Q_{2}\right)+\left(S^{f}-\tilde{S}\right) X-C\left(Q_{1}+Q_{2}\right)
$$

The forward position, $X$, is said to be an under-hedge, a full-hedge, or an over-hedge, depending on whether $X$ is smaller than, equal to, or greater than the foreign currency revenue, $R_{2}\left(Q_{2}\right)$, respectively. The multinational firm possesses a von Neumann-Morgenstern utility function, $U(\Pi)$, defined over its home currency profit at date 1 , $\Pi$, with $U^{\prime}(\Pi)>0$ and $U^{\prime \prime}(\Pi)<0$, indicating the presence of risk aversion.

The multinational firm faces ambiguity in that it is uncertain about the objective CDF, $F^{\circ}(S)$. Succinctly, the multinational firm has a continuum of priors, $\{F(S \mid \theta): \theta \in[\underline{\theta}, \bar{\theta}]\}$, where $F(S \mid \theta)$ denotes a plausible first-order CDF of $\tilde{S}$ over support $[\underline{S}, \bar{S}]$, which is sensitive to a parameter, $\theta$, whose value is not known ex ante. Based on its subjective information, the multinational firm associates a second-order CDF, $G(\theta)$, over the continuum of priors, i.e., over support $[\underline{\theta}, \bar{\theta}]$, where $-\infty \leq \underline{\theta}<\bar{\theta} \leq \infty$. This captures the multinational firm's uncertainty about which of the first-order CDF, $F(S \mid \theta)$, governs the exchange rate risk, $\tilde{S}$.

Following Gollier (2011), Snow (2010, 2011), and Wong (2015, 2016), we assume that the

\footnotetext{
${ }^{7}$ Engel and Rogers (1996, 2001) and Parsley and Wei (1996) provide supportive evidence that arbitrage transactions among national markets are indeed imperfect.

${ }^{8}$ Throughout the paper, random variables have a tilde $(\sim)$ while their realizations do not.

${ }^{9}$ It is equally legitimate to interpret the random variable, $\tilde{S}$, as a multiplicative shock to the multinational firm's foreign currency revenue, $R_{2}\left(Q_{2}\right)$, such as political risk, economic risk, or credit risk, as long as this risk is either hedgeable or insurable.
} 
multinational firm's ambiguous beliefs are unbiased in the sense that the expected exchange rate risk is equal to the objective exchange rate risk:

$$
\int_{\underline{\theta}}^{\bar{\theta}} F(S \mid \theta) \mathrm{d} G(\theta)=F^{\circ}(S)
$$

for all $S \in[\underline{S}, \bar{S}] \cdot{ }^{10}$ We denote $\mathrm{E}_{F}(\cdot \mid \theta), \mathrm{E}_{G}(\cdot)$, and $\mathrm{E}_{F^{\circ}}(\cdot)$, as the expectation operators with respect to the first-order $\mathrm{CDF}, F(S \mid \theta)$, the second-order CDF, $G(\theta)$, and the objective $\mathrm{CDF}, F^{\circ}(S)$, respectively.

The recursive structure of the KMM model implies that we can compute the multinational firm's expected utility under ambiguity in three steps. First, we calculate the multinational firm's expected utility for each first-order CDF of $\tilde{S}, \mathrm{E}_{F}[U(\tilde{\Pi}) \mid \theta]$, where $\tilde{\Pi}$ is given by Eq. (5). Second, we transform each first-order expected utility obtained in the first sept by an ambiguity function, $\phi(U)$, where $\phi^{\prime}(U)>0$ and $U$ is the multinational firm's utility level. Finally, we take the expectation of the transformed first-order expected utility obtained in the second step with respect to the second-order CDF of $\tilde{\theta}$. The multinational firm's ex-ante decision problem as such is given by

$$
\max _{Q_{1} \geq 0, Q_{2} \geq 0, X} \int_{\underline{\theta}}^{\bar{\theta}} \phi\left\{\mathrm{E}_{F}[U(\tilde{\Pi}) \mid \theta]\right\} \mathrm{d} G(\theta) .
$$

Inspection of the objective function of program (3) reveals that the effect of ambiguity, represented by the second-order CDF, $G(\theta)$, and the effect of ambiguity preferences, represented by the shape of the ambiguity function, $\phi(U)$, can be separated and thus studied independently.

The multinational firm is said to be ambiguity averse if, for any given triple, $\left(Q_{1}, Q_{2}, X\right)$, the objective function of program (3) decreases when the multinational firm's ambiguous beliefs, specified by $G(\theta)$, change in a way that induces a mean-preserving spread in the distribution of the multinational firm's expected utility. According to this definition, Klibanoff

\footnotetext{
${ }^{10}$ The assumption that the expected exchange rate risk is equal to the objective exchange rate risk can be motivated by the premise that the behavior of an ambiguity-neutral decision maker should be unaffected by the introduction of, or changes in, ambiguity.
} 
et al. (2005) show that ambiguity aversion implies concavity for $\phi(U)$, and that a concave transformation of $\phi(U)$ results in greater ambiguity aversion. ${ }^{11}$ To see this, we define the ambiguity aversion premium, $P$, as the solution to the following equation:

$$
\int_{\underline{\theta}}^{\bar{\theta}} \phi\left\{\mathrm{E}_{F}[U(\tilde{\Pi}) \mid \theta]\right\} \mathrm{d} G(\theta)=\phi\left\{\int_{\underline{\theta}}^{\bar{\theta}} \mathrm{E}_{F}[U(\tilde{\Pi}) \mid \theta] \mathrm{d} G(\theta)-P\right\} .
$$

Hence, $P$ measures the "pain" the multinational firm is willing to suffer in order to get rid of ambiguity. It follows from Eq. (4) and Jensen's inequality that $P>0$ if, and only if, $\phi^{\prime \prime}(U)<0$. To compare ambiguity aversion, we define the ambiguity aversion premium, $P_{i}$, as the solution to the following equation:

$$
\int_{\underline{\theta}}^{\bar{\theta}} \phi_{i}\left\{\mathrm{E}_{F}[U(\tilde{\Pi}) \mid \theta]\right\} \mathrm{d} G(\theta)=\phi_{i}\left\{\int_{\underline{\theta}}^{\bar{\theta}} \mathrm{E}_{F}[U(\tilde{\Pi}) \mid \theta] \mathrm{d} G(\theta)-P_{i}\right\},
$$

for $i=1$ and 2. It follows from Eq. (5) and Pratt (1964) that $P_{1}<P_{2}$ if, and only if, $-\phi_{1}^{\prime \prime}(U) / \phi_{1}^{\prime}(U)<-\phi_{2}^{\prime \prime}(U) / \phi_{2}^{\prime}(U)$, which is equivalent to $\phi_{2}(U)$ being a concave transformation of $\phi_{1}(U)$. Throughout the paper, we assume that $\phi^{\prime \prime}(U)<0$ so that the firm is ambiguity averse.

\section{Solution to the model}

The first-order conditions for program (3) are given by

$$
\begin{aligned}
& \int_{\underline{\theta}}^{\bar{\theta}} \phi^{\prime}\left\{\mathrm{E}_{F}\left[U\left(\tilde{\Pi}^{*}\right) \mid \theta\right]\right\} \mathrm{E}_{F}\left\{U^{\prime}\left(\tilde{\Pi}^{*}\right)\left[R_{1}^{\prime}\left(Q_{1}^{*}\right)-C^{\prime}\left(Q_{1}^{*}+Q_{2}^{*}\right)\right] \mid \theta\right\} \mathrm{d} G(\theta)=0 \\
& \int_{\underline{\theta}}^{\bar{\theta}} \phi^{\prime}\left\{\mathrm{E}_{F}\left[U\left(\tilde{\Pi}^{*}\right) \mid \theta\right]\right\} \mathrm{E}_{F}\left\{U^{\prime}\left(\tilde{\Pi}^{*}\right)\left[\tilde{S} R_{2}^{\prime}\left(Q_{2}^{*}\right)-C^{\prime}\left(Q_{1}^{*}+Q_{2}^{*}\right)\right] \mid \theta\right\} \mathrm{d} G(\theta)=0
\end{aligned}
$$

and

$$
\int_{\underline{\theta}}^{\bar{\theta}} \phi^{\prime}\left\{\mathrm{E}_{F}\left[U\left(\tilde{\Pi}^{*}\right) \mid \theta\right]\right\} \mathrm{E}_{F}\left[U^{\prime}\left(\tilde{\Pi}^{*}\right)\left(S^{f}-\tilde{S}\right) \mid \theta\right] \mathrm{d} G(\theta)=0,
$$

\footnotetext{
${ }^{11}$ When $\phi(U)=[1-\exp (-\alpha U)] / \alpha$, Klibanoff et al. (2005) show that the maxmin expected utility model of Gilboa and Schmeidler (1989) is the limiting case as the constant absolute ambiguity aversion, $\alpha$, approaches infinity under some conditions.
} 
where $\tilde{\Pi}^{*}=R_{1}\left(Q_{1}^{*}\right)+\tilde{S} R_{2}\left(Q_{2}^{*}\right)+\left(S^{f}-\tilde{S}\right) X^{*}-C\left(Q_{1}^{*}+Q_{2}^{*}\right), Q_{1}^{*}$ and $Q_{2}^{*}$ are the optimal amounts of domestic sales and foreign exports, respectively, and $X^{*}$ is the optimal forward position. The second-order conditions for program (3) are satisfied given the assumed properties of $\phi(U), U(\Pi), C(Q)$, and $R_{i}\left(Q_{i}\right)$ for $i=1$ and 2 .

Since $\phi^{\prime}(U)>0$ and $U^{\prime}(\Pi)>0$, Eq. (6) reduces to

$$
R_{1}^{\prime}\left(Q_{1}^{*}\right)=C^{\prime}\left(Q_{1}^{*}+Q_{2}^{*}\right)
$$

Multiplying $R_{2}^{\prime}\left(Q_{2}^{*}\right)$ to Eq. (8) and adding the resulting equation to Eq. (7) yields

$$
S^{f} R_{2}^{\prime}\left(Q_{2}^{*}\right)=C^{\prime}\left(Q_{1}^{*}+Q_{2}^{*}\right)
$$

since $\phi^{\prime}(U)>0$ and $U^{\prime}(\Pi)>0$. Eqs. (9) and (10) imply that the multinational firm's optimal production and export decisions depend on the predetermined forward exchange rate and the cost and revenue functions, but are independent of the degree of ambiguity and the prevalence of ambiguity preferences.

Suppose that the multinational firm adopts a full-hedge, i.e., $X^{*}=R_{2}\left(Q_{2}^{*}\right)$. Then, the left-hand side of Eq. (8) becomes

$$
\phi^{\prime}\left[U\left(\bar{\Pi}^{*}\right)\right] U^{\prime}\left(\bar{\Pi}^{*}\right)\left[S^{f}-\int_{\underline{\theta}}^{\bar{\theta}} \mathrm{E}_{F}(\tilde{S} \mid \theta) \mathrm{d} G(\theta)\right]=\phi^{\prime}\left[U\left(\bar{\Pi}^{*}\right)\right] U^{\prime}\left(\bar{\Pi}^{*}\right)\left[S^{f}-\mathrm{E}_{F^{\circ}}(\tilde{S})\right],
$$

where $\bar{\Pi}^{*}=R_{1}\left(Q_{1}^{*}\right)+S^{f} R_{2}\left(Q_{2}^{*}\right)-C\left(Q_{1}^{*}+Q_{2}^{*}\right)$, and the equality follows from Eq. (2). Hence, Eqs. (8) and (11) imply that $X^{*}$ is less than, equal to, or greater than $R_{2}\left(Q_{2}^{*}\right)$, depending on whether $S^{f}$ is less than, equal to, or greater than $\mathrm{E}_{F^{\circ}}(\tilde{S})$, respectively.

We summarize the above results in our first proposition.

Proposition 1. If the ambiguity-averse multinational firm can trade the foreign currency forward at the predetermined forward exchange rate, $S^{f}$, the firm's optimal amounts of domestic sales, $Q_{1}^{*}$, and foreign exports, $Q_{2}^{*}$, simultaneously solve Eqs. (9) and (10). The ambiguity-averse multinational firm's optimal forward position, $X^{*}$, is an under-hedge, a 
full-hedge, or an over-hedge, depending on whether $S^{f}$ is less than, equal to, or greater than the objective expected value of $\tilde{S}, \mathrm{E}_{F^{\circ}}(\tilde{S})$, respectively.

The intuition for Proposition 1 is as follows. Since the multinational firm can always sell the last unit of its foreign currency revenue forward at the predetermined forward exchange rate, $S^{f}$, the usual optimality condition applies in that the marginal cost of production, $C^{\prime}\left(Q_{1}^{*}+Q_{2}^{*}\right)$, must be equated to the known marginal revenue at home, $R_{1}^{\prime}\left(Q_{1}^{*}\right)$, and that in the foreign market, $S^{f} R_{2}^{\prime}\left(Q_{2}^{*}\right)$, which determines the optimal amounts of domestic sales, $Q_{1}^{*}$, and foreign exports, $Q_{2}^{*}$. If $S^{f}$ is unbiased in that it is equal to $\mathrm{E}_{F^{\circ}}(\tilde{S})$, the objective expected value of $\tilde{S}$, the multinational firm, being risk averse and ambiguity averse, has a hedging motive to adopt a full-hedge, i.e., $X^{*}=R_{2}\left(Q_{2}^{*}\right)$, that completely eliminates the exchange rate risk, $\tilde{S}$, thereby the exposure to ambiguity. On the other hand, if $S^{f}$ is less (greater) than $\mathrm{E}_{F^{\circ}}(\tilde{S})$, the multinational firm has a speculative motive to opt for a long (short) forward position so as to take advantage of the positive (negative) expected risk premium, $\mathrm{E}_{F^{\circ}}(\tilde{S})-S^{f}$. Combining the two motives, the multinational firm as such optimally chooses $X^{*}$ to be below (above) $R_{2}\left(Q_{2}^{*}\right)$ whenever $S^{f}<(>) \mathrm{E}_{F^{\circ}}(\tilde{S})$.

Since $\phi^{\prime \prime}(U)<0$, Jensen's inequality implies that

$$
\int_{\underline{\theta}}^{\bar{\theta}} \phi\left\{\mathrm{E}_{F}\left[U\left(\tilde{\Pi}^{*}\right) \mid \theta\right]\right\} \mathrm{d} G(\theta) \leq \phi\left\{\int_{\underline{\theta}}^{\bar{\theta}} \mathrm{E}_{F}\left[U\left(\tilde{\Pi}^{*}\right) \mid \theta\right] \mathrm{d} G(\theta)\right\}
$$

where, from Proposition 1 , the inequality holds with equality only when $S^{f}=\mathrm{E}_{F^{\circ}}(\tilde{S})$. In the absence of ambiguity, the multinational firm knows the objective CDF of $\tilde{S}$ so that $F(S \mid \theta)=F^{\circ}(S)$ for all $S \in[\underline{S}, \bar{S}]$ and $\theta \in[\underline{\theta}, \bar{\theta}]$. In this case, the results of Proposition 1 remain valid so that the multinational firm's optimal amounts of domestic sales and foreign exports are $Q_{1}^{*}$ and $Q_{2}^{*}$, respectively. The multinational firm's optimal forward position becomes $X^{\circ}$, which is the solution to the following equation:

$$
\mathrm{E}_{F^{\circ}}\left[U^{\prime}\left(\tilde{\Pi}^{\circ}\right)\left(S^{f}-\tilde{S}\right)\right]=0
$$

where $\tilde{\Pi}^{\circ}=R_{1}\left(Q_{1}^{*}\right)+\tilde{S} R_{2}\left(Q_{2}^{*}\right)+\left(S^{f}-\tilde{S}\right) X^{\circ}-C\left(Q_{1}^{*}+Q_{2}^{*}\right)$. It follows from Eqs. (8) and 
(13) that $X^{\circ}=X^{*}=R_{2}\left(Q_{2}^{*}\right)$ if $S^{f}=\mathrm{E}_{F^{\circ}}(\tilde{S})$, and $X^{\circ}$ may or may not be equal to $X^{*}$ otherwise. ${ }^{12}$ Hence, we have

$$
\phi\left\{\mathrm{E}_{F^{\circ}}\left[U\left(\tilde{\Pi}^{\circ}\right)\right]\right\} \geq \phi\left\{\mathrm{E}_{F^{\circ}}\left[U\left(\tilde{\Pi}^{*}\right)\right]\right\}=\phi\left\{\int_{\underline{\theta}}^{\bar{\theta}} \mathrm{E}_{F}\left[U\left(\tilde{\Pi}^{*}\right) \mid \theta\right] \mathrm{d} G(\theta)\right\}
$$

where the equality follows from Eq. (2), and inequality holds with equality if $X^{\circ}=X^{*}$. The following proposition is a direct consequence of Eqs. (12) and (14).

Proposition 2. The presence of ambiguity always makes the ambiguity-averse multinational firm worse off given that the firm can only trade the foreign currency forward at a biased forward exchange rate, i.e., $S^{f} \neq \mathrm{E}_{F^{\circ}}(\tilde{S})$. The ambiguity-averse multinational firm is indifferent between the presence and the absence of ambiguity given that the firm can trade the foreign currency forward at the biased forward exchange rate, i.e., $S^{f}=\mathrm{E}_{F^{\circ}}(\tilde{S})$.

The intuition for Proposition 2 is as follows. When the forward exchange rate is biased, i.e., $S^{f} \neq \mathrm{E}_{F^{\circ}}(\tilde{S})$, there is a speculative motive that induces the multinational firm not to completely eliminate the exchange rate risk. The presence of ambiguity as such creates additional risk that makes the ambiguity-averse multinational firm worse off as compared to the case without ambiguity. When the forward exchange rate is unbiased, i.e., $S^{f}=\mathrm{E}_{F^{\circ}}(\tilde{S})$, the speculative motive disappears and the multinational firm finds it optimal to completely eliminate the exchange rate risk, thereby making the presence of ambiguity irrelevant.

\section{Firm behavior and currency hedging}

In this section, we examine the effect of currency hedging on the multinational firm's production and export decisions. To this end, we examine a benchmark case wherein the multinational firm is banned from trading the foreign currency forward so that $X \equiv 0$.

\footnotetext{
${ }^{12}$ See Proposition 3 in Section 4 for an explicit comparison between $X^{\circ}$ and $X^{*}$ when $S^{f} \neq \mathrm{E}_{F^{\circ}}(\tilde{S})$.
} 
In this case, the multinational firm's optimal amounts of domestic sales, $Q_{1}^{n}$, and foreign exports, $Q_{2}^{n}$, solve the following first-order conditions:

$$
\int_{\underline{\theta}}^{\bar{\theta}} \phi^{\prime}\left\{\mathrm{E}_{F}\left[U\left(\tilde{\Pi}^{n}\right) \mid \theta\right]\right\} \mathrm{E}_{F}\left\{U^{\prime}\left(\tilde{\Pi}^{n}\right)\left[R_{1}^{\prime}\left(Q_{1}^{n}\right)-C^{\prime}\left(Q_{1}^{n}+Q_{2}^{n}\right)\right] \mid \theta\right\} \mathrm{d} G(\theta)=0
$$

and

$$
\int_{\underline{\theta}}^{\bar{\theta}} \phi^{\prime}\left\{\mathrm{E}_{F}\left[U\left(\tilde{\Pi}^{n}\right) \mid \theta\right]\right\} \mathrm{E}_{F}\left\{U^{\prime}\left(\tilde{\Pi}^{n}\right)\left[\tilde{S} R_{2}^{\prime}\left(Q_{2}^{n}\right)-C^{\prime}\left(Q_{1}^{n}+Q_{2}^{n}\right)\right] \mid \theta\right\} \mathrm{d} G(\theta)=0,
$$

where $\tilde{\Pi}^{n}=R_{1}\left(Q_{1}^{n}\right)+\tilde{S} R_{2}\left(Q_{2}^{n}\right)-C\left(Q_{1}^{n}+Q_{2}^{n}\right)$.

We compare the multinational firm's optimal production and export decisions with and without the currency hedging opportunity in the following proposition.

Proposition 3. If the following condition holds:

$$
\int_{\underline{\theta}}^{\bar{\theta}} \phi^{\prime}\left\{\mathrm{E}_{F}\left[U\left(\tilde{\Pi}^{n}\right) \mid \theta\right]\right\} \mathrm{E}_{F}\left[U^{\prime}\left(\tilde{\Pi}^{n}\right)\left(S^{f}-\tilde{S}\right) \mid \theta\right] \mathrm{d} G(\theta)>0
$$

allowing the ambiguity-averse multinational firm to trade the foreign currency forward at the predetermined forward exchange rate, $S^{f}$, results in a decrease in the optimal amount of domestic sales, i.e., $Q_{1}^{*}<Q_{1}^{\circ}$, an increase in the optimal amount of foreign exports, i.e., $Q_{2}^{*}>Q_{2}^{\circ}$, and an increase in the optimal output level, i.e., $Q_{1}^{*}+Q_{2}^{*}>Q_{1}^{\circ}+Q_{2}^{\circ}$.

Proof. Since $\phi^{\prime}(U)>0$ and $U^{\prime}(\Pi)>0$, Eq. (15) reduces to

$$
R_{1}^{\prime}\left(Q_{1}^{n}\right)=C^{\prime}\left(Q_{1}^{n}+Q_{2}^{n}\right)
$$

Recast Eq. (16) as

$$
\begin{aligned}
& S^{f} R_{2}^{\prime}\left(Q_{2}^{n}\right)-C^{\prime}\left(Q_{1}^{n}+Q_{2}^{n}\right) \\
& =\frac{\int_{\underline{\theta}}^{\bar{\theta}} \phi^{\prime}\left\{\mathrm{E}_{F}\left[U\left(\tilde{\Pi}^{n}\right) \mid \theta\right]\right\} \mathrm{E}_{F}\left[U^{\prime}\left(\tilde{\Pi}^{n}\right)\left(S^{f}-\tilde{S}\right) \mid \theta\right] \mathrm{d} G(\theta) R_{2}^{\prime}\left(Q_{2}^{n}\right)}{\int_{\underline{\theta}}^{\bar{\theta}} \phi^{\prime}\left\{\mathrm{E}_{F}\left[U\left(\tilde{\Pi}^{n}\right) \mid \theta\right]\right\} \mathrm{E}_{F}\left[U^{\prime}\left(\tilde{\Pi}^{n}\right) \mid \theta\right] \mathrm{d} G(\theta)} .
\end{aligned}
$$


It then follows from condition (17) and Eq. (19) that $S^{f} R_{2}^{\prime}\left(Q_{2}^{n}\right)>C^{\prime}\left(Q_{1}^{n}+Q_{2}^{n}\right)$.

Suppose that $Q_{2}^{n} \geq Q_{2}^{*}$ so that $S^{f} R_{2}^{\prime}\left(Q_{2}^{n}\right) \leq S^{f} R_{2}^{\prime}\left(Q_{2}^{*}\right)$. Since $S^{f} R_{2}^{\prime}\left(Q_{2}^{n}\right)>C^{\prime}\left(Q_{1}^{n}+Q_{2}^{n}\right)$ and $S^{f} R_{2}^{\prime}\left(Q_{2}^{*}\right)=C^{\prime}\left(Q_{1}^{*}+Q_{2}^{*}\right)$, we have $C^{\prime}\left(Q_{1}^{n}+Q_{2}^{n}\right)<C^{\prime}\left(Q_{1}^{*}+Q_{2}^{*}\right)$, implying that $Q_{1}^{n}+Q_{2}^{n}<$ $Q_{1}^{*}+Q_{2}^{*}$. It then follows from Eqs. (9) and (18) that $R_{1}^{\prime}\left(Q_{1}^{n}\right)<R_{1}^{\prime}\left(Q_{1}^{*}\right)$ so that $Q_{1}^{n}>Q_{1}^{*}$. But we have $Q_{2}^{n} \geq Q_{2}^{*}$ so that $Q_{1}^{n}+Q_{2}^{n}>Q_{1}^{*}+Q_{2}^{*}$, a contradiction. Hence, it must be true that $Q_{2}^{n}<Q_{2}^{*}$.

Suppose now that $Q_{1}^{n} \leq Q_{1}^{*}$ so that $R_{1}^{\prime}\left(Q_{1}^{n}\right) \geq R_{1}^{\prime}\left(Q_{1}^{*}\right)$. It then follows from Eqs. (9) and (18) that $Q_{1}^{n}+Q_{2}^{n} \geq Q_{1}^{*}+Q_{2}^{*}$. From above, we have $Q_{2}^{n}<Q_{2}^{*}$ so that $Q_{1}^{n}+Q_{2}^{n}<Q_{1}^{*}+Q_{2}^{*}$, a contradiction. Hence, it must be true that $Q_{1}^{n}>Q_{1}^{*}$.

From above, we have $Q_{1}^{n}>Q_{1}^{*}$ so that $R_{1}^{\prime}\left(Q_{1}^{n}\right)<R_{1}^{\prime}\left(Q_{1}^{*}\right)$. It then follows from Eqs. (9) and (18) that $Q_{1}^{n}+Q_{2}^{n}<Q_{1}^{*}+Q_{2}^{*}$.

To see the meaning of condition (17), we define $Q_{1}(X)$ and $Q_{2}(X)$ as the solution to program (3) for a fixed forward position, $X$. When $X=0$, we have $Q_{1}(0)=Q_{1}^{n}$ and $Q_{2}(0)=Q_{2}^{n}$. When $X=X^{*}$, we have $Q_{1}\left(X^{*}\right)=Q_{1}^{*}$ and $Q_{2}\left(X^{*}\right)=Q_{2}^{*}$. Substituting $Q_{1}=Q_{1}(X)$ and $Q_{2}=Q_{2}(X)$ into the objective function of program (3), we differentiate the objective function with respect to $X$, and evaluate the resulting derivative at $X=0$ to yield

$$
\begin{aligned}
& \left.\frac{\partial}{\partial X} \int_{\underline{\theta}}^{\bar{\theta}} \phi\left\{\mathrm{E}_{F}[U(\tilde{\Pi}) \mid \theta]\right\} \mathrm{d} G(\theta)\right|_{Q_{1}=Q_{1}(X), Q_{2}=Q_{2}(X), X=0} \\
& =\int_{\underline{\theta}}^{\bar{\theta}} \phi^{\prime}\left\{\mathrm{E}_{F}\left[U\left(\tilde{\Pi}^{n}\right) \mid \theta\right]\right\} \mathrm{E}_{F}\left[U^{\prime}\left(\tilde{\Pi}^{n}\right)\left(S^{f}-\tilde{S}\right) \mid \theta\right] \mathrm{d} G(\theta),
\end{aligned}
$$

where we have used the envelop theorem and the fact that $Q_{1}(0)=Q_{1}^{n}$ and $Q_{2}(0)=Q_{2}^{n}$. If $X^{*}>0$, it follows from Eq. (8) that the right-hand side of Eq. (20) must be positive, and thus condition (17) holds. We can interpret the right-hand side of Eq. (19) as the certainty equivalent risk premium that takes the multinational firm's smooth ambiguity preferences into account. Condition (17) ensures that this risk premium is positive so that 
the multinational firm has incentives to sell the foreign currency forward, i.e., $X^{*}>0$, at the

predetermined forward exchange rate, $S^{f}$. From Proposition 1, we have $X^{*} \geq R_{2}\left(Q_{2}^{*}\right)>0$ whenever $S^{f} \geq \mathrm{E}_{F^{\circ}}(\tilde{S})$. Hence, as long as $S^{f}$ is not too small compared to $\mathrm{E}_{F^{\circ}}(\tilde{S})$, it must be true that $X^{*}>0$. In this case, the multinational firm optimally sells the foreign currency forward and thus its exchange rate risk exposure is reduced. As such, the multinational firm is willing to increase its optimal output level, i.e., $Q_{1}^{*}+Q_{2}^{*}>Q_{1}^{n}+Q_{2}^{n}$, and to raise its optimal amount of foreign exports, i.e., $Q_{2}^{*}>Q_{2}^{n}$, at the expense of a reduction of domestic sales, i.e., $Q_{1}^{*}<Q_{1}^{n}$.

If condition (17) is violated in that

$$
\int_{\underline{\theta}}^{\bar{\theta}} \phi^{\prime}\left\{\mathrm{E}_{F}\left[U\left(\tilde{\Pi}^{n}\right) \mid \theta\right]\right\} \mathrm{E}_{F}\left[U^{\prime}\left(\tilde{\Pi}^{n}\right)\left(S^{f}-\tilde{S}\right) \mid \theta\right] \mathrm{d} G(\theta)<0,
$$

it follows from Eq. (20) that $X^{*}<0$. Given condition (21), one can analogously show that the multinational firm optimally sells more at home, i.e., $Q_{1}^{*}>Q_{1}^{n}$, exports less to the foreign country, i.e., $Q_{2}^{*}<Q_{2}^{n}$, and produces less in the home country, i.e., $Q_{1}^{*}+Q_{2}^{*}<Q_{1}^{n}+Q_{2}^{n}$, if it is allowed to trade the foreign currency forward at the predetermined forward exchange rate, $S^{f}$. This case, however, is of less interest because it would imply that the multinational firm buys the foreign currency forward to augment (not reduce) its exchange rate risk exposure.

\section{Ambiguity and currency hedging}

From Proposition 1, we know that the separation and full-hedging theorems hold irrespective of whether ambiguity is present or not. Hence, to examine the effect of ambiguity on the multinational firm's behavior, we compare the multinational firm's optimal forward position in the presence of ambiguity, $X^{*}$, to that in the absence of ambiguity, $X^{\circ}$, when the predetermined forward exchange rate, $S^{f}$, is biased, i.e., $S^{f} \neq \mathrm{E}_{F^{\circ}}(\tilde{S})$.

Substituting $Q_{1}=Q_{1}^{*}$ and $Q_{2}=Q_{2}^{*}$ into the objective function of program (3), we differentiate the objective function with respect to $X$ and evaluate the resulting derivative 
at $X=X^{\circ}$ to yield

$$
\begin{aligned}
& \left.\frac{\partial}{\partial X} \int_{\underline{\theta}}^{\bar{\theta}} \phi\left\{\mathrm{E}_{F}[U(\tilde{\Pi}) \mid \theta]\right\} \mathrm{d} G(\theta)\right|_{Q_{1}=Q_{1}^{*}, Q_{2}=Q_{2}^{*}, X=X^{\circ}} \\
= & \int_{\underline{\theta}}^{\bar{\theta}} \phi^{\prime}\left\{\mathrm{E}_{F}\left[U\left(\tilde{\Pi}^{\circ}\right) \mid \theta\right]\right\} \mathrm{E}_{F}\left[U^{\prime}\left(\tilde{\Pi}^{\circ}\right)\left(S^{f}-\tilde{S}\right) \mid \theta\right] \mathrm{d} G(\theta) \\
= & \int_{\underline{\theta}}^{\bar{\theta}} \phi^{\prime}\left\{\mathrm{E}_{F}\left[U\left(\tilde{\Pi}^{\circ}\right) \mid \theta\right]\right\} \mathrm{d} G(\theta) \mathrm{E}_{F^{\circ}}\left[U^{\prime}\left(\tilde{\Pi}^{\circ}\right)\left(S^{f}-\tilde{S}\right)\right] \\
& +\operatorname{Cov}_{G}\left\{\phi^{\prime}\left\{\mathrm{E}_{F}\left[U\left(\tilde{\Pi}^{\circ}\right) \mid \tilde{\theta}\right]\right\}, \mathrm{E}_{F}\left[U^{\prime}\left(\tilde{\Pi}^{\circ}\right)\left(S^{f}-\tilde{S}\right) \mid \tilde{\theta}\right]\right\} \\
= & \operatorname{Cov}_{G}\left\{\phi^{\prime}\left\{\mathrm{E}_{F}\left[U\left(\tilde{\Pi}^{\circ}\right) \mid \tilde{\theta}\right]\right\}, \mathrm{E}_{F}\left[U^{\prime}\left(\tilde{\Pi}^{\circ}\right)\left(S^{f}-\tilde{S}\right) \mid \tilde{\theta}\right]\right\},
\end{aligned}
$$

where $\tilde{\Pi}^{\circ}=R_{1}\left(Q_{1}^{*}\right)+\tilde{S} R_{2}\left(Q_{2}^{*}\right)+\left(S^{f}-\tilde{S}\right) X^{\circ}-C\left(Q_{1}^{*}+Q_{2}^{*}\right)$, the first equality follows from Eq. (2), the second equality follows from Eq. (13), and $\operatorname{Cov}_{G}(\cdot, \cdot)$ is the covariance operator with respect to the second-order CDF, $G(\theta)$. When $S^{f}<\mathrm{E}_{F^{\circ}}(\tilde{S})$, it follows from Eq. (8) and Proposition 1 that $X^{\circ}<X^{*}<R_{2}\left(Q_{2}^{*}\right)$ if, and only if, the covariance term on the right-hand side of Eq. (22) is positive. On the other hand, when $S^{f}>\mathrm{E}_{F^{\circ}}(\tilde{S})$, it follows from Eq. (8) and Proposition 1 that $X^{\circ}>X^{*}>R_{2}\left(Q_{2}^{*}\right)$ if, and only if, the covariance term on the right-hand side of Eq. (22) is negative. We as such establish the following proposition.

Proposition 4. When the predetermined forward exchange rate, $S^{f}$, is smaller (greater) than the objective expected value of $\tilde{S}, \mathrm{E}_{F^{\circ}}(\tilde{S})$, introducing ambiguity to the ambiguity-averse multinational firm renders the optimal forward position, $X^{*}$, to be closer to a full-hedge if, and only if, the covariance between $\phi^{\prime}\left\{\mathrm{E}_{F}\left[U\left(\tilde{\Pi}^{\circ}\right) \mid \tilde{\theta}\right]\right\}$ and $\mathrm{E}_{F}\left[U^{\prime}\left(\tilde{\Pi}^{\circ}\right)\left(S^{f}-\tilde{S}\right) \mid \tilde{\theta}\right]$ is positive (negative).

To see the intuition for Proposition 4, we write Eq. (13) as

$$
S^{f}=\mathrm{E}_{F^{\circ}}(\tilde{S})+\frac{\operatorname{Cov}_{F^{\circ}}\left[U^{\prime}\left(\tilde{\Pi}^{\circ}\right), \tilde{S}\right]}{\mathrm{E}_{F^{\circ}}\left[U^{\prime}\left(\tilde{\Pi}^{\circ}\right)\right]},
$$


where $\operatorname{Cov}_{F^{\circ}}(\cdot, \cdot)$ is the covariance operator with respect to the objective $\operatorname{CDF}, F^{\circ}(S)$. Eq. (23) states that the multinational firm's optimal forward position, $X^{\circ}$, is the one that equates the predetermined forward exchange rate to the certainty equivalent spot exchange rate at date 1 . We can interpret the second term on the right-hand side of Eq. (23) as the risk premium demanded by the multinational firm to compensate for its exposure to the exchange rate risk. Using Eq. (2), we can write Eq. (22) as

$$
\begin{aligned}
& \left.\quad \frac{\partial}{\partial X} \int_{\underline{\theta}}^{\bar{\theta}} \phi\left\{\mathrm{E}_{F}[U(\tilde{\Pi}) \mid \theta]\right\} \mathrm{d} G(\theta)\right|_{Q_{1}=Q_{1}^{*}, Q_{2}=Q_{2}^{*}, X=X^{\circ}} \\
& =\mathrm{E}_{G}\left\{\phi^{\prime}\left\{\mathrm{E}_{F}\left[U\left(\tilde{\Pi}^{\circ}\right) \mid \tilde{\theta}\right]\right\}\right\} \mathrm{E}_{F^{\circ}}\left[U^{\prime}\left(\tilde{\Pi}^{\circ}\right)\right]\left\{S^{f}-\mathrm{E}_{F^{\circ}}(\tilde{S})-\frac{\operatorname{Cov}_{F^{\circ}}\left[U^{\prime}\left(\tilde{\Pi}^{\circ}\right), \tilde{S}\right]}{\mathrm{E}_{F^{\circ}}\left[U^{\prime}\left(\tilde{\Pi}^{\circ}\right)\right]}\right. \\
& \left.\quad+\frac{\operatorname{Cov}_{G}\left\{\phi^{\prime}\left\{\mathrm{E}_{F}\left[U\left(\tilde{\Pi}^{\circ}\right) \mid \tilde{\theta}\right]\right\}, \mathrm{E}_{F}\left[U^{\prime}\left(\tilde{\Pi}^{\circ}\right)\left(S^{f}-\tilde{S}\right) \mid \tilde{\theta}\right]\right\}}{\mathrm{E}_{G}\left\{\phi^{\prime}\left\{\mathrm{E}_{F}\left[U\left(\tilde{\Pi}^{\circ}\right) \mid \tilde{\theta}\right]\right\}\right\} \mathrm{E}_{F^{\circ}}\left[U^{\prime}\left(\tilde{\Pi}^{\circ}\right)\right]}\right\} .
\end{aligned}
$$

We can interpret the last term inside the curly brackets on the right-hand side of Eq. (24) as the ambiguity premium demanded by the multinational firm to compensate for its exposure to ambiguity at $X=X^{\circ}$. Given that the covariance between $\phi^{\prime}\left\{\mathrm{E}_{F}\left[U\left(\tilde{\Pi}^{\circ}\right) \mid \tilde{\theta}\right]\right\}$ and $\mathrm{E}_{F}\left[U^{\prime}\left(\tilde{\Pi}^{\circ}\right)\left(S^{f}-\tilde{S}\right) \mid \tilde{\theta}\right]$ is positive (negative), the ambiguity premium is positive (negative) so that the certainty equivalent spot exchange rate at date 1 is smaller (greater) than the predetermined forward exchange rate at $X=X^{\circ}$. To restore the optimality condition, the multinational firm is induced to sell more (less) than $X^{\circ}$ in response to the introduction of ambiguity. Hence, we have $X^{\circ}<X^{*}<R_{2}\left(Q_{2}^{*}\right)$ when $S^{f}<\mathrm{E}_{F^{\circ}}(\tilde{S})$ and $X^{\circ}>X^{*}>R_{2}\left(Q_{2}^{*}\right)$ when $S^{f}>\mathrm{E}_{F^{\circ}}(\tilde{S})$.

To show that the necessary and sufficient conditions as stated in Proposition 4 hold under reasonable scenarios, we focus on the case wherein the multinational firm's coefficient of relative risk aversion, $\Phi(\Pi)=-\Pi U^{\prime \prime}(\Pi) / U^{\prime}(\Pi)$, does not exceed unity for all $\Pi>0$, and the parameter, $\theta$, ranks the first-order CDF, $F(S \mid \theta)$, in the sense of first-order stochastic dominance. Using integration by parts, we differentiate $\phi^{\prime}\left\{\mathrm{E}_{F}\left[U\left(\tilde{\Pi}^{\circ}\right) \mid \theta\right]\right\}$ with respect to $\theta$ 
to yield

$$
\frac{\partial}{\partial \theta} \phi^{\prime}\left\{\mathrm{E}_{F}\left[U\left(\tilde{\Pi}^{\circ}\right) \mid \theta\right]\right\}=\int_{\underline{S}}^{\bar{S}} \phi^{\prime \prime}\left\{\mathrm{E}_{F}\left[U\left(\tilde{\Pi}^{\circ}\right) \mid \theta\right]\right\} U^{\prime}\left(\Pi^{\circ}\right)\left[X^{\circ}-R_{2}\left(Q_{2}^{*}\right)\right] F_{\theta}(S \mid \theta) \mathrm{d} S,
$$

where $F_{\theta}(S \mid \theta)=\partial F(S \mid \theta) / \partial \theta$. When $S^{f}<(>) \mathrm{E}_{F^{\circ}}(\tilde{S})$, we have $X^{\circ}<(>) R_{2}\left(Q_{2}^{*}\right)$ from Proposition 1. It then follows from Eq. (25) that $\partial \phi^{\prime}\left\{\mathrm{E}_{F}\left[U\left(\tilde{\Pi}^{\circ}\right) \mid \theta\right]\right\} / \partial \theta$ has the same sign as (opposite sign to) that of $F_{\theta}(S \mid \theta)$ when $S^{f}<(>) \mathrm{E}_{F^{\circ}}(\tilde{S})$. Likewise, using integration by parts, we differentiate $\mathrm{E}_{F}\left[U^{\prime}\left(\tilde{\Pi}^{\circ}\right)\left(S^{f}-\tilde{S}\right) \mid \theta\right]$ with respect to $\theta$ to yield

$$
\frac{\partial}{\partial \theta} \mathrm{E}_{F}\left[U^{\prime}\left(\tilde{\Pi}^{\circ}\right)\left(S^{f}-\tilde{S}\right) \mid \theta\right]=\int_{\underline{S}}^{\bar{S}}\left\{U^{\prime}\left(\Pi^{\circ}\right)\left[1-\Phi\left(\Pi^{\circ}\right)\right]-U^{\prime \prime}\left(\Pi^{\circ}\right) \bar{\Pi}^{*}\right\} F_{\theta}(S \mid \theta) \mathrm{d} S,
$$

where $\bar{\Pi}^{*}=R_{1}\left(Q_{1}^{*}\right)+S^{f} R_{2}\left(Q_{2}^{*}\right)-C\left(Q_{1}^{*}+Q_{2}^{*}\right)$. Since $\Phi(\Pi) \leq 1$ for all $\Pi>0$, Eq. (26) implies that $\partial \mathrm{E}_{F}\left[U^{\prime}\left(\tilde{\Pi}^{\circ}\right)\left(S^{f}-\tilde{S}\right) \mid \theta\right] / \partial \theta$ has the same sign as that of $F_{\theta}(S \mid \theta)$. Hence, the covariance between $\phi^{\prime}\left\{\mathrm{E}_{F}\left[U\left(\tilde{\Pi}^{\circ}\right) \mid \tilde{\theta}\right]\right\}$ and $\mathrm{E}_{F}\left[U^{\prime}\left(\tilde{\Pi}^{\circ}\right)\left(S^{f}-\tilde{S}\right) \mid \tilde{\theta}\right]$ is indeed positive (negative) when $S^{f}<(>) \mathrm{E}_{F^{\circ}}(\tilde{S})$.

Klibanoff et al. (2005) show that the multinational firm becomes more ambiguity averse when $\phi(U)$ is replaced by $K[\phi(U)]$ in the objective function of program (3), where $K(\cdot)$ satisfies that $K^{\prime}(\cdot)>0$ and $K^{\prime \prime}(\cdot)<0$. The more ambiguity-averse multinational firm's ex-ante decision problem is given by

$$
\max _{Q_{1} \geq 0, Q_{2} \geq 0, X} \int_{\underline{\theta}}^{\bar{\theta}} K\left\{\phi\left\{\mathrm{E}_{F}[U(\tilde{\Pi}) \mid \theta]\right\}\right\} \mathrm{d} G(\theta)
$$

From Proposition 1, we know that the separation and full-hedging theorems hold irrespective of the multinational firm's ambiguity aversion. The multinational firm's optimal forward position becomes $X^{\diamond}$, which is the solution to the following equation:

$$
\int_{\underline{\theta}}^{\bar{\theta}} K^{\prime}\left\{\phi\left\{\mathrm{E}_{F}\left[U\left(\tilde{\Pi}^{\diamond}\right) \mid \theta\right]\right\}\right\} \phi^{\prime}\left\{\mathrm{E}_{F}\left[U\left(\tilde{\Pi}^{\diamond}\right) \mid \theta\right]\right\} \mathrm{E}_{F}\left[U^{\prime}\left(\tilde{\Pi}^{\diamond}\right)\left(S^{f}-\tilde{S}\right) \mid \tilde{\theta}\right] \mathrm{d} G(\theta)=0
$$

where $\tilde{\Pi}^{\diamond}=R_{1}\left(Q_{1}^{*}\right)+\tilde{S} R_{2}\left(Q_{2}^{*}\right)+\left(S^{f}-\tilde{S}\right) X^{\diamond}-C\left(Q_{1}^{*}+Q_{2}^{*}\right)$. Hence, to examine the effect of greater ambiguity aversion on the multinational firm's optimal forward position, we compare $X^{\diamond}$ to $X^{*}$ when the predetermined forward exchange rate, $S^{f}$, is biased, i.e., $S^{f} \neq \mathrm{E}_{F^{\circ}}(\tilde{S})$. 
Substituting $Q_{1}=Q_{1}^{*}$ and $Q_{2}=Q_{2}^{*}$ into the objective function of program (27), we differentiate the objective function with respect to $X$ and evaluate the resulting derivative at $X=X^{*}$ to yield

$$
\begin{aligned}
& \left.\frac{\partial}{\partial X} \int_{\underline{\theta}}^{\bar{\theta}} K\left\{\phi\left\{\mathrm{E}_{F}[U(\tilde{\Pi}) \mid \theta]\right\}\right\} \mathrm{d} G(\theta)\right|_{Q_{1}=Q_{1}^{*}, Q_{2}=Q_{2}^{*}, X=X^{*}} \\
= & \int_{\underline{\theta}}^{\bar{\theta}} K^{\prime}\left\{\phi\left\{\mathrm{E}_{F}\left[U\left(\tilde{\Pi}^{*}\right) \mid \theta\right]\right\}\right\} \phi^{\prime}\left\{\mathrm{E}_{F}\left[U\left(\tilde{\Pi}^{*}\right) \mid \theta\right]\right\} \mathrm{E}_{F}\left[U^{\prime}\left(\tilde{\Pi}^{*}\right)\left(S^{f}-\tilde{S}\right) \mid \tilde{\theta}\right] \mathrm{d} G(\theta) \\
= & \int_{\underline{\theta}}^{\bar{\theta}} K^{\prime}\left\{\phi\left\{\mathrm{E}_{F}\left[U\left(\tilde{\Pi}^{*}\right) \mid \theta\right]\right\}\right\} \mathrm{d} G(\theta) \int_{\underline{\theta}}^{\bar{\theta}} \phi^{\prime}\left\{\mathrm{E}_{F}\left[U\left(\tilde{\Pi}^{*}\right) \mid \theta\right]\right\} \mathrm{E}_{F}\left[U^{\prime}\left(\tilde{\Pi}^{*}\right)\left(S^{f}-\tilde{S}\right) \mid \tilde{\theta}\right] \mathrm{d} G(\theta) \\
& +\operatorname{Cov}_{G}\left\{K^{\prime}\left\{\phi\left\{\mathrm{E}_{F}\left[U\left(\tilde{\Pi}^{*}\right) \mid \tilde{\theta}\right]\right\}\right\}, \phi^{\prime}\left\{\mathrm{E}_{F}\left[U\left(\tilde{\Pi}^{*}\right) \mid \tilde{\theta}\right]\right\} \mathrm{E}_{F}\left[U^{\prime}\left(\tilde{\Pi}^{*}\right)\left(S^{f}-\tilde{S}\right) \mid \tilde{\theta}\right]\right\} \\
= & \operatorname{Cov}_{G}\left\{K^{\prime}\left\{\phi\left\{\mathrm{E}_{F}\left[U\left(\tilde{\Pi}^{*}\right) \mid \tilde{\theta}\right]\right\}\right\}, \phi^{\prime}\left\{\mathrm{E}_{F}\left[U\left(\tilde{\Pi}^{*}\right) \mid \tilde{\theta}\right]\right\} \mathrm{E}_{F}\left[U^{\prime}\left(\tilde{\Pi}^{*}\right)\left(S^{f}-\tilde{S}\right) \mid \tilde{\theta}\right]\right\}
\end{aligned}
$$

where $\tilde{\Pi}^{*}=R_{1}\left(Q_{1}^{*}\right)+\tilde{S} R_{2}\left(Q_{2}^{*}\right)+\left(S^{f}-\tilde{S}\right) X^{*}-C\left(Q_{1}^{*}+Q_{2}^{*}\right)$, the second equality follows from Eq. (8). When $S^{f}<\mathrm{E}_{F^{\circ}}(\tilde{S})$, it follows from Eq. (28) and Proposition 1 that $X^{*}<X^{\diamond}<R_{2}\left(Q_{2}^{*}\right)$ if, and only if, the covariance term on the right-hand side of Eq. (29) is positive. On the other hand, when $S^{f}>\mathrm{E}_{F^{\circ}}(\tilde{S})$, it follows from Eq. (28) and Proposition 1 that $X^{*}>X^{\diamond}>R_{2}\left(Q_{2}^{*}\right)$ if, and only if, the covariance term on the right-hand side of Eq. (29) is negative. We as such establish the following proposition.

Proposition 5. When the predetermined forward exchange rate, $S^{f}$, is smaller (greater) than the objective expected value of $\tilde{S}, \mathrm{E}_{F^{\circ}}(\tilde{S})$, making the ambiguity-averse exporting firm more ambiguity averse by replacing $\phi(U)$ by $K[\phi(U)]$ renders the optimal forward position, $X^{\diamond}$, to be closer to a full-hedge if, and only if, the covariance between $K^{\prime}\left\{\phi\left\{\mathrm{E}_{F}\left[U\left(\tilde{\Pi}^{*}\right) \mid \tilde{\theta}\right]\right\}\right\}$ and $\phi^{\prime}\left\{\mathrm{E}_{F}\left[U\left(\tilde{\Pi}^{*}\right) \mid \tilde{\theta}\right]\right\} \mathrm{E}_{F}\left[U^{\prime}\left(\tilde{\Pi}^{*}\right)\left(S^{f}-\tilde{S}\right) \mid \tilde{\theta}\right]$ is positive (negative).

To see the intuition for Proposition 5, we write Eq. (8) as 


$$
\begin{aligned}
S^{f}= & \mathrm{E}_{F^{\circ}}(\tilde{S})+\frac{\operatorname{Cov}_{F^{\circ}}\left[U^{\prime}\left(\tilde{\Pi}^{*}\right), \tilde{S}\right]}{\mathrm{E}_{F^{\circ}}\left[U^{\prime}\left(\tilde{\Pi}^{*}\right)\right]} \\
& -\frac{\operatorname{Cov}_{G}\left\{\phi^{\prime}\left\{\mathrm{E}_{F}\left[U\left(\tilde{\Pi}^{*}\right) \mid \tilde{\theta}\right]\right\}, \mathrm{E}_{F}\left[U^{\prime}\left(\tilde{\Pi}^{*}\right)\left(S^{f}-\tilde{S}\right) \mid \tilde{\theta}\right]\right\}}{\mathrm{E}_{G}\left\{\phi^{\prime}\left\{\mathrm{E}_{F}\left[U\left(\tilde{\Pi}^{*}\right) \mid \tilde{\theta}\right]\right\}\right\} \mathrm{E}_{F^{\circ}}\left[U^{\prime}\left(\tilde{\Pi}^{*}\right)\right]} .
\end{aligned}
$$

Eq. (30) states that the multinational firm's optimal forward position, $X^{*}$, is the one that equates the predetermined forward exchange rate to the certainty equivalent spot exchange rate at date 1. Using Eq. (2), we can write Eq. (29) as

$$
\begin{aligned}
& \left.\frac{\partial}{\partial X} \int_{\underline{\theta}}^{\bar{\theta}} K\left\{\phi\left\{\mathrm{E}_{F}[U(\tilde{\Pi}) \mid \theta]\right\}\right\} \mathrm{d} G(\theta)\right|_{Q_{1}=Q_{1}^{*}, Q_{2}=Q_{2}^{*}, X=X^{*}} \\
& =\mathrm{E}_{G}\left\{K^{\prime}\left\{\phi\left\{\mathrm{E}_{F}\left[U\left(\tilde{\Pi}^{*}\right) \mid \tilde{\theta}\right]\right\}\right\}\right\} \mathrm{E}_{G}\left\{\phi^{\prime}\left\{\mathrm{E}_{F}\left[U\left(\tilde{\Pi}^{*}\right) \mid \tilde{\theta}\right]\right\}\right\} \mathrm{E}_{F^{\circ}}\left[U^{\prime}\left(\tilde{\Pi}^{*}\right)\right]\left\{S^{f}-\mathrm{E}_{F^{\circ}}(\tilde{S})\right. \\
& \quad-\frac{\operatorname{Cov}_{F^{\circ}}\left[U^{\prime}\left(\tilde{\Pi}^{*}\right), \tilde{S}\right]}{\mathrm{E}_{F^{\circ}}\left[U^{\prime}\left(\tilde{\Pi}^{*}\right)\right]}+\frac{\operatorname{Cov}_{G}\left\{\phi^{\prime}\left\{\mathrm{E}_{F}\left[U\left(\tilde{\Pi}^{*}\right) \mid \tilde{\theta}\right]\right\}, \mathrm{E}_{F}\left[U^{\prime}\left(\tilde{\Pi}^{*}\right)\left(S^{f}-\tilde{S}\right) \mid \tilde{\theta}\right]\right\}}{\mathrm{E}_{G}\left\{\phi^{\prime}\left\{\mathrm{E}_{F}\left[U\left(\tilde{\Pi}^{*}\right) \mid \tilde{\theta}\right]\right\}\right\} \mathrm{E}_{F^{\circ}}\left[U^{\prime}\left(\tilde{\Pi}^{*}\right)\right]} \\
& \left.+\frac{\operatorname{Cov}_{G}\left\{K^{\prime}\left\{\phi\left\{\mathrm{E}_{F}\left[U\left(\tilde{\Pi}^{*}\right) \mid \tilde{\theta}\right]\right\}\right\}, \phi^{\prime}\left\{\mathrm{E}_{F}\left[U\left(\tilde{\Pi}^{*}\right) \mid \tilde{\theta}\right]\right\} \mathrm{E}_{F}\left[U^{\prime}\left(\tilde{\Pi}^{*}\right)\left(S^{f}-\tilde{S}\right) \mid \tilde{\theta}\right]\right\}}{\mathrm{E}_{G}\left\{K^{\prime}\left\{\phi\left\{\mathrm{E}_{F}\left[U\left(\tilde{\Pi}^{*}\right) \mid \tilde{\theta}\right]\right\}\right\}\right\} \mathrm{E}_{G}\left\{\phi^{\prime}\left\{\mathrm{E}_{F}\left[U\left(\tilde{\Pi}^{*}\right) \mid \tilde{\theta}\right]\right\}\right\} \mathrm{E}_{F^{\circ}}\left[U^{\prime}\left(\tilde{\Pi}^{*}\right)\right]}\right\}
\end{aligned}
$$

We can interpret the last term inside the curly brackets on the right-hand side of Eq. (31) as the additional ambiguity premium demanded by the multinational firm to compensate for its exposure to ambiguity at $X=X^{*}$ due to greater ambiguity aversion. Given that the covariance between $K^{\prime}\left\{\phi\left\{\mathrm{E}_{F}\left[U\left(\tilde{\Pi}^{*}\right) \mid \tilde{\theta}\right]\right\}\right\}$ and $\left.\phi^{\prime}\left\{\mathrm{E}_{F}\left[U\left(\tilde{\Pi}^{*}\right) \mid \tilde{\theta}\right]\right\} \mathrm{E}_{F}\left[U^{\prime}\left(\tilde{\Pi}^{*}\right)\left(S^{f}-\tilde{S}\right) \mid \tilde{\theta}\right]\right\}$ is positive (negative), the additional ambiguity premium is positive (negative) so that the certainty equivalent spot exchange rate at date 1 is smaller (greater) than the predetermined forward exchange rate at $X=X^{*}$. To restore the optimality condition, the multinational firm is induced to sell more (less) than $X^{*}$ in response to greater ambiguity aversion. Hence, we have $X^{*}<X^{\diamond}<R_{2}\left(Q_{2}^{*}\right)$ when $S^{f}<\mathrm{E}_{F^{\circ}}(\tilde{S})$ and $X^{*}>X^{\diamond}>R_{2}\left(Q_{2}^{*}\right)$ when $S^{f}>$ $\mathrm{E}_{F^{\circ}}(\tilde{S})$.

To show that the necessary and sufficient conditions as stated in Proposition 5 hold under reasonable scenarios, we focus on the case wherein the multinational firm's coefficient 
of relative risk aversion, $\Phi(\Pi)=-\Pi U^{\prime \prime}(\Pi) / U^{\prime}(\Pi)$, does not exceed unity for all $\Pi>0$, and an increase in the parameter, $\theta$, always deteriorates the first-order $\operatorname{CDF}, F(S \mid \theta)$, in the sense of first-order stochastic dominance, i.e., $F_{\theta}(S \mid \theta) \geq 0$ for all $S \in[\underline{S}, \bar{S}]$ and $\theta \in[\underline{\theta}, \bar{\theta}] .{ }^{13}$ Using integration by parts, we differentiate $K^{\prime}\left\{\varphi\left\{\mathrm{E}_{F}\left[U\left(\tilde{\Pi}^{*}\right) \mid \theta\right]\right\}\right\}$ with respect to $\theta$ to yield

$$
\begin{aligned}
& \frac{\partial}{\partial \theta} K^{\prime}\left\{\varphi\left\{\mathrm{E}_{F}\left[U\left(\tilde{\Pi}^{*}\right) \mid \theta\right]\right\}\right\} \\
& =K^{\prime \prime}\left\{\varphi\left\{\mathrm{E}_{F}\left[U\left(\tilde{\Pi}^{*}\right) \mid \theta\right]\right\}\right\} \varphi^{\prime}\left\{\mathrm{E}_{F}\left[U\left(\tilde{\Pi}^{*}\right) \mid \theta\right]\right\} \int_{\underline{S}}^{\bar{S}} U^{\prime}\left(\Pi^{*}\right)\left[X^{*}-R_{2}\left(Q_{2}^{*}\right)\right] F_{\theta}(S \mid \theta) \mathrm{d} S .
\end{aligned}
$$

When $S^{f}<(>) \mathrm{E}_{F^{\circ}}(\tilde{S})$, we have $X^{*}<(>) R_{2}\left(Q_{2}^{*}\right)$ from Proposition 1. Since $F_{\theta}(S \mid \theta) \geq 0$ for all $S \in[\underline{S}, \bar{S}]$ and $\theta \in[\underline{\theta}, \bar{\theta}]$, Eq. (32) implies that $\partial K^{\prime}\left\{\varphi\left\{\mathrm{E}_{F}\left[U\left(\tilde{\Pi}^{*}\right) \mid \theta\right]\right\}\right\} / \partial \theta>(<) 0$ when $S^{f}<(>) \mathrm{E}_{F^{\circ}}(\tilde{S})$. Using integration by parts, we differentiate $\mathrm{E}_{F}\left\{U^{\prime}\left(\tilde{\Pi}^{*}\right)\left(S^{f}-\tilde{S}\right) \mid \theta\right\}$ with respect to $\theta$ to yield

$$
\frac{\partial}{\partial \theta} \mathrm{E}_{F}\left\{U^{\prime}\left(\tilde{\Pi}^{*}\right)\left(S^{f}-\tilde{S}\right) \mid \theta\right\}=\int_{\underline{S}}^{\bar{S}}\left\{U^{\prime}\left(\Pi^{*}\right)\left[1-\Phi\left(\Pi^{*}\right)\right]-U^{\prime \prime}\left(\Pi^{*}\right) \bar{\Pi}^{*}\right\} F_{\theta}(S \mid \theta) \mathrm{d} S
$$

where $\bar{\Pi}^{*}=R_{1}\left(Q_{1}^{*}\right)+S^{f} R_{2}\left(Q_{2}^{*}\right)-C\left(Q_{1}^{*}+Q_{2}^{*}\right)$. Since $\Phi(\Pi) \leq 1$ for all $\Pi>0$ and $F_{\theta}(S \mid \theta) \geq 0$ for all $S \in[\underline{S}, \bar{S}]$ and $\theta \in[\underline{\theta}, \bar{\theta}]$, Eq. (33) implies that $\partial \mathrm{E}_{F}\left[U^{\prime}\left(\tilde{\Pi}^{*}\right)\left(S^{f}-\tilde{S}\right) \mid \theta\right] / \partial \theta>0$. Hence, there must exist a unique point, $\theta_{1} \in(\underline{\theta}, \bar{\theta})$ such that $\mathrm{E}_{F}\left[U^{\prime}\left(\tilde{\Pi}^{*}\right)\left(S^{f}-\tilde{S}\right) \mid \theta\right]<(>) 0$ for all $\theta<(>) \theta_{1}$. Using Eq. (8), we can write the right-hand side of Eq. (29) as

$$
\begin{aligned}
\int_{\underline{\theta}}^{\bar{\theta}}\left\{K ^ { \prime } \left\{\phi \left\{\mathrm{E}_{F}[\right.\right.\right. & \left.\left.\left.\left.U\left(\tilde{\Pi}^{*}\right) \mid \theta\right]\right\}\right\}-K^{\prime}\left\{\phi\left\{\mathrm{E}_{F}\left[U\left(\tilde{\Pi}^{*}\right) \mid \theta_{1}\right]\right\}\right\}\right\} \\
\times & \phi^{\prime}\left\{\mathrm{E}_{F}\left[U\left(\tilde{\Pi}^{*}\right) \mid \theta\right]\right\} \mathrm{E}_{F}\left[U^{\prime}\left(\tilde{\Pi}^{*}\right)\left(S^{f}-\tilde{S}\right) \mid \theta\right] \mathrm{d} G(\theta) .
\end{aligned}
$$

When $S^{f}<(>) \mathrm{E}_{F^{\circ}}(\tilde{S})$, we have $\partial K^{\prime}\left\{\phi\left\{\mathrm{E}_{F}\left[U\left(\tilde{\Pi}^{*}\right) \mid \theta\right]\right\}\right\} / \partial \theta>(<) 0$ so that Eq. (34) must be positive (negative). It then follows from Eq. (29) that the covariance between $K^{\prime}\left\{\phi\left\{\mathrm{E}_{F}\left[U\left(\tilde{\Pi}^{*}\right) \mid \tilde{\theta}\right]\right\}\right\}$ and $\phi^{\prime}\left\{\mathrm{E}_{F}\left[U\left(\tilde{\Pi}^{*}\right) \mid \tilde{\theta}\right]\right\} \mathrm{E}_{F}\left[U^{\prime}\left(\tilde{\Pi}^{*}\right)\left(S^{f}-\tilde{S}\right) \mid \tilde{\theta}\right\}$ is indeed positive (negative) when $S^{f}<(>) \mathrm{E}_{F^{\circ}}(\tilde{S})$.

\footnotetext{
${ }^{13}$ The case wherein an increase in $\theta$ always improves the first-order CDF, $F(S \mid \theta)$, in the sense of first-order stochastic dominance gives the same result.
} 
Before leaving this section, it is worth pointing out the difference between the impact of risk aversion and that of ambiguity aversion. If the multinational firm is purely risk averse, it is well-known that greater risk aversion always induces the multinational firm to adopt a forward position that is closer to a full-hedge (Holthausen, 1979) given that the forward exchange rate is biased. However, this result holds under ambiguity aversion if, and only if, the necessary and sufficient conditions stated in Proposition 5 are satisfied. As shown above, if the multinational firm's coefficient of relative risk aversion, $\Phi(\Pi)=-\Pi U^{\prime \prime}(\Pi) / U^{\prime}(\Pi)$, far exceeds unity, the necessary and sufficient conditions stated in Proposition 5 would be violated. In this case, greater ambiguity aversion would then induce the multinational firm to opt for a forward position that is further away from a full-hedge given that the forward exchange rate is biased.

\section{Conclusion}

In this paper, we examine the production and hedging decisions of the multinational firm under exchange rate uncertainty à la Broll and Zilcha (1992). The multinational firm produces in the home country and sells its output in both the home and foreign markets. To hedge against the exchange rate risk, the multinational firm can trade the foreign currency forward at a predetermined forward exchange rate. The multinational firm's preferences exhibit smooth ambiguity aversion developed by Klibanoff et al. (2005). Ambiguity is represented by a second-order probability distribution that captures the multinational firm's uncertainty about which of the subjective beliefs govern the exchange rate risk. On the other

hand, ambiguity preferences are modeled by the (second-order) expectation of a concave transformation of the (first-order) expected utility of home currency profit conditional on each plausible subjective distribution of the exchange rate risk.

We show that the separation and full-hedging theorems are robust to the prevalence of ambiguity and ambiguity preferences. The multinational firm optimally produces more 
and sells less at home, and exports more abroad in the presence than in the absence of the currency hedging opportunity. Given that the forward exchange rate is biased, we derive necessary and sufficient conditions under which the multinational firm optimally opts for a forward position that is closer to a full-hedge in response to either the introduction of ambiguity or greater ambiguity aversion. These necessary and sufficient conditions are satisfied when the multinational firm's coefficient of relative risk aversion does not exceed unity and its subjective beliefs are ranked in the sense of first-order stochastic dominance.

In this paper, we model the exchange rate risk in a reduced form by assuming that the multinational firm commits to its export decision made prior to the resolution of the exchange rate uncertainty. This specification ignores the fact that the exchange rate risk is likely to be linked to factors such as economic growth, inflation, interest rates, and employment that also drive the profitability of the multinational firm in reality. Taking these factors into account requires a general equilibrium approach, which is an interesting and important extension. Another plausible extension is to expose the multinational firm to other sources of uncertainty such as political (and regulatory) risk, economic risk, and credit risk. Indeed, not much has been done for the decision making under multiple sources of ambiguity (Wong, 2016a, 2016b). We leave these challenges for future research.

\section{Acknowledgements}

I would like to thank Udo Broll, Carl Chen (the editor), and an anonymous referee for their helpful comments and suggestions. The usual disclaimer applies.

\section{References}

Alary, D., Gollier, C., \& Treich, N. (2013). The effect of ambiguity aversion on insurance and self-protection. Economic Journal, 123, 1188-1202. 
Barham, B. L., Chavas, J.-P., Fitz, D., Salas, V. R., \& Schechter, L. (2014). The role of risk and ambiguity in technology adoption. Journal of Economic Behavior and Organization, 97, 204-218.

Bodnar, G. M., Hayt, G. S., \& Marston, R. C. (1998). 1998 Wharton survey of financial risk management by US non-financial firms. Financial Management, 27, 70-91.

Broll, U. (1992). The effect of forward markets on multinational firms. Bulletin of Economic Research, 44, 233-240.

Broll, U., \& Wong, K. P. (2015). The incentive to trade under ambiguity aversion. Journal of Economic Asymmetries, 12, 190-196.

Broll, U., \& Zilcha, I. (1992). Exchange rate uncertainty, futures markets and the multinational firm. European Economic Review, 36, 815-826.

Cardenas, J. C., \& Carpenter, J. (2008). Behavioural development economics: Lessons from field labs in the developing world. Journal of Development Studies, 44, 311-338.

Cherbonnier, F., \& Gollier, C. (2015). Decreasing aversion under ambiguity. Journal of Economic Theory, 157, 606-623.

Chesson, H. W., \& Viscusi, W. K. (2003). Commonalities in time and ambiguity aversion for long-term risks. Journal of Risk and Uncertainty, 24, 57-71.

Choe, C., Lien, D., \& Yu, C.-F. (2015). Optimal managerial hedging and contracting with self-esteem concerns. International Review of Economics and Finance, 37, 354-367.

Chow, C. C., \& Sarin, R. K. (2001). Comparative ignorance and the Ellsberg Paradox. Journal of Risk and Uncertainty, 22, 129-139.

Dillenberger, D., \& Segal, U. (2015). Recursive ambiguity and Machina's examples. International Economic Review, 56, 55-61.

Einhorn, H. J., \& Hogarth, R. M. (1986). Decision making under ambiguity. Journal of Business, 59, S225-S250. 
Ellsberg, D. (1961). Risk, ambiguity, and the Savage axioms. Quarterly Journal of Economics, 75, 643-669.

Engel, C., \& Rogers, J. H. (1996). How wide is the border? American Economic Review, $86,1112-1125$.

Engel, C., \& Rogers, J. H. (2001). Violating the law of one price: should we make a Federal case out of it? Journal of Money, Credit and Banking, 33, 1-15.

Gilboa, I., \& Schmeidler, D. (1989). Maxmin expected utility with a non-unique prior. Journal of Mathematical Economics, 18, 141-153.

Gollier, C. (2011). Portfolio choices and asset prices: the comparative statics of ambiguity aversion. Review of Economic Studies, 78, 1329-1344.

Holthausen, D. M. (1979). Hedging and the competitive firm under price uncertainty. American Economic Review, 69, 989-995.

Jesswein, K. R., Kwok, C. C. Y., \& Folk, W. R. (1995). Corporate use of innovative foreign exchange risk management products. Columbia Journal of World Business, 30, 70-82.

Katz, E., \& Paroush, J. (1979). The effect of forward markets on exporting firms. Economics Letters, 4, 272-274.

Kawai, M., \& Zilcha, I. (1986). International trade with forward-futures markets under exchange rate and price uncertainty. Journal of International Economics, 20, 83-98.

Keynes, J. M. (1921). A treatise on probability. London: Macmillan.

Klibanoff, P., Marinacci, M., \& Mukerji, S. (2005). A smooth model of decision making under ambiguity. Econometrica, 73, 1849-1892.

Knight, F. H. (1921). Risk, uncertainty and profit. Boston: Houghton Mifflin.

Lien, D., \& Wong, K. P. (2005). Multinationals and futures hedging under liquidity constraints. Global Finance Journal, 16, 210-220. 
Machina, M. J. (2014). Ambiguity aversion with three or more outcomes. American Economic Review, 104, 3814-3840.

Meng, R., \& Wong, K. P. (2007). Currency hedging for multinationals under liquidity constraints. Journal of Multinational Financial Management, 17, 417-431.

Parsley, D. C., \& Wei, S. J. (1996). Convergence to the law of one price without trade barriers or currency fluctuations. Quarterly Journal of Economics, 111, 1211-1236.

Pratt, J. W. (1964). Risk aversion in the small and in the large. Econometrica, 32, 122-136.

Sarin, R. K., \& Weber, M. (1993). Effects of ambiguity in market experiments. Management Science, 39, 602-615.

Skiadas, C. (2013). Smooth ambiguity aversion toward small risks and continuous-time recursive utility. Journal of Political Economy, 121, 775-792.

Snow, A. (2010). Ambiguity and the value of information. Journal of Risk and Uncertainty, 40, 133-145.

Snow, A. (2011). Ambiguity aversion and the propensities for self-insurance and selfprotection. Journal of Risk and Uncertainty, 42, 27-43.

Taboga, M. (2005). Portfolio selection with two-stage preferences. Finance Research Letters, 2, 152-164.

Treich, N. (2010). The value of a statistical life under ambiguity aversion. Journal of Environmental Economics and Management, 59, 15-26.

Viaene, J.-M., \& Zilcha, I. (1998). The behavior of competitive exporting firms under multiple uncertainty. International Economic Review, 39, 591-609.

Viscusi, W. K., \& Chesson, H. W. (1999). Hopes and fears: the conflicting effects of risk ambiguity. Theory and Decision, 47, 153-178.

Wong, K. P. (2012). Production and futures hedging with state-dependent background risk. International Review of Economics and Finance, 24, 177-184. 
Wong, K. P. (2013). International trade and hedging under joint price and exchange rate uncertainty. International Review of Economics and Finance, 27, 160-170.

Wong, K. P. (2015a). Ambiguity and the value of hedging. Journal of Futures Markets, 35, $839-848$.

Wong, K. P. (2015b). A smooth ambiguity model of the competitive firm. Bulletin of Economic Research, 67, S97-S110.

Wong, K. P. (2016a). Production and hedging under smooth ambiguity preferences. Journal of Futures Markets, 36, 506-518.

Wong, K. P. (2016b). Cross-hedging ambiguous exchange rate risk. Journal of Futures Markets, 36, in press. 